\title{
Comparison of Dietary Behavior according to the Count of Allergic Diseases in Korean Adolescents
}

\author{
Soon Hee Kim11), Youngju Jee²) \\ 한국 청소년의 알레르기 질환 수에 따른 식생활 행태비교 \\ 김순희 ${ }^{1)}$, 지영주2)
}

\begin{abstract}
The purpose of this study is to compare dietary behavior according to the number of allergic diseases in Korean adolescents. This study used the raw data from the 15th (2019) Korea Youth Risk Behavior Web-based Survey selected 57,303 young adults aged 12-18 years. The results of the study showed that adolescents' eating habits according to the number of allergic diseases in adolescents during the past year showed statistically significant difference in breakfast when comparing eating habits of one, two and three allergic diseases $(\mathrm{F}=5.491, \mathrm{p}=.004)$. In addition, when comparing the three groups, allergic diseases tended to increase in carbonated drinks $(p<.001)$, energy drinks $(p<.001)$, sweet drinks $(p=.001)$, and fast food groups $(p<.001)$, and there was a statistically significant difference. Therefore, it will be important to clearly understand the eating habits of adolescents in the future and to prepare positive eating habits to improve their eating habits, and to take measures to stabilize their choices and relieve stress.
\end{abstract}

Keywords: Adolescent, Eating behavior, Allergic Diseasea, Food Habits

$$
\text { 요약 }
$$

본 연구의 목적은 우리나라 청소년의 알레르기 질환 수에 따른 식생활 행태를 비교 연구하고자 하는 것이다. 본 연구는 제15차(2019년) 청소년건강행태 온라인조사의 원시자료를 이용하였으며 만12-18세 청소년 57,303 명을 연구대상자로 선정하였다. 연구결과는 최근 1 년간 청소년의 알레르기 질환 수에 따른 청소년 식생활 행태를 비교한 결과 알레르기 질환이 하나, 두 개, 세 개인 집단의 식생활 행태 를 비교했을 때 아침 식사를 하는 집단에서 통계적으로 유의한 차이가 나타났다 $(\mathrm{F}=5.491, p=004)$. 또 한 세 군을 비교했을 때 탄산음료 $(p<.001)$, 에너지음료( $p<.001)$, 단맛이 나는 음료( $p=001)$, 패스트푸드 군의 섭취 빈도( $p<001)$ 가 높은 집단이 알레르기 질환이 증가하는 경향을 보였으며 통계적으로 유의

Received(June 7, 2020), Review Result(1st: July 28, 2020, 2nd: September 19, 2020), Accepted(October 28, 2020)

1) (Associate professor) 47230 Department of Nursing, Dong-Eui Institute of Technology, Yangji-ro 5beon-gil, Busanjin-gu, Busan, Korea

email: ozblood@dit.ac.kr

2) (Assistant Professor, Corresponding Author) 51767 Kyungnam University, College of Nursing, Woryeongbuk 16-gil, Masanhappo-gu, Changwon-si, Gyeongsangnam-do, Korea

email: jeeyoungju@kyungnam.ac.kr 


\section{Comparison of Dietary Behavior according to the Number of Allergic Diseases in Korean Adolescents}

한 차이를 보였다. 따라서, 앞으로 청소년의 식생활을 명확히 파악하여 식생활 개선을 위한 긍정적인 식습관 및 정신적 안정과 스트레스 해소를 위한 대책 마련이 무엇보다 주요할 것으로 생각된다.

핵심어: 청소년, 식생활 행태, 알레르기 질환, 식습관

\section{1. 서론}

\section{1 연구의 필요성}

사람 살아가는 성장 주기에서 가장 먼저 접하게 되는 만성질환이 알레르기 질환이다. 이는 어떠한 이물질에 대한 신체가 과도한 면역반응을 보이는 것으로, 알레르기가 반응이 나타내는 기관에 따 라 발현되며. 천식, 알레르기비염, 아토피피부염이 대표적이다[1][2]. 2015년도 통계청 조사에 따르 면 우리나라 청소년의 알레르기 질환은 천식 $8.8 \%$, 알레르기 비염 $33.2 \%$, 아토피 피부염 $24.2 \%$ 로 2007년 천식 $8.5 \%$, 알레르기비염 $24.5 \%$, 아토피 피부염 $17.3 \%$ 에 비해 모두 유병률이 증가하였다[3]. 하지만 대부분이 생명에 지장이 없는 증상들을 보여 다른 질환들에 비해 과소평가되면서 이에 대 한 관리 또한 부족한 실정이다[4][5].

청소년기는 신체적, 정신적, 영적 측면에서 급성장하는 시기로 성인기에 큰 영향을 미치게 되며 한 인간의 삶의 질을 결정하는 중요한 시기로 여겨지고 있다. 특히 이 시기의 식생활 행태는 한번 형성된 식습관의 변화도 어렵고 신체적 발육뿐만 아니라 심리 및 정서 발달에도 큰 영향을 미치게 된다[6]. 그러나 최근 청소년 식생활 행태 연구에 따르면 이 시기에 학업 및 자기 과업에 대한 과 중한 임무로 아침을 거르거나 고열량의 인스턴트식품 섭취, 패스트푸드 음식 및 편의점 이용 등 불규칙한 식습관과 부적절한 음식 섭취로 영양 불균형이 심각한 것으로 보고되고 있다[7]. 2017년 도 제 13 차 청소년건강행태온라인조사 통계자료를 보면 패스트푸드 섭취율은 $20.5 \%$ 로 증가하는 경 향을 확인할 수 있었고 $40 \%$ 이상의 학생은 주 1 2회 정도 편의점, 매점 등에서 면류, 음료수 등의 식사 대용의 음식을 먹는 것으로 국내 청소년 건강 행태에서 식생활의 불균형 문제가 매우 심각하 게 대두되고 있는 현실이다[8].

알레르기가 없는 청소년에 비해 알레르기 질환이 있는 청소년이 스트레스, 우울감에 대한 경험, 자살에 관한 생각 가능성이 크고[9], 알레르기 질환이 있는 경우에 질환이 없는 경우보다 1.84 배 정신과 문제 수준이 높게 나타나며, 1 개 알레르기 질환을 가지고 있으면 1.56 배, 2 개 가지고 있을 경우 2.20배, 2개 이상 가지고 있으면 3.39배 높게 나타난다고 보고되고 있다[10]. 그러므로 청소년 들의 정신 건강 문제로 알레르기 질환이 악화하지 않도록 중재 방안 마련이 필요하며, 대상자들이 정서적으로 민감한 시기임을 고려하여 학교 기반의 별도 프로그램을 통한 접근이 요구되고 있다 [9].

최근 생활패턴이 서구화되면서 전통적인 음식보다는 빠르고 간편하게 조리해서 먹을 수 있는 간편식을 먹는 서구화된 식습관의 변화가 알레르기 질환의 유병률 증대에 기여했을 것으로 생각된 다. 청소년기 식습관은 한번 형성되면 변화하기 어려우므로 질병 발생이나 평생의 생활 패턴에 영 
향을 줄 수 있기 때문에 어릴 적 올바른 식습관을 형성해주는 것이 중요하다[11].

국내 청소년을 대상으로 알레르기 질환의 유병률 및 영향요인에 관한 연구는 많이 진행된 상황 이지만 알레르기 질환 수에 따른 청소년건강행태 연구는 미비하다. 따라서 본 연구는 제 15 차( 2019년) 청소년건강행태온라인조사(Korea Youth Risk Behavior Web-based Survey)의 원시자료를 이용하여 우리나라 청소년의 알레르기 질환 수에 따른 식생활 행태를 비교 연구하고자 한다.

\section{2 연구 목적}

본 연구의 목적은 우리나라 청소년의 알레르기 질환 수에 따른 식생활 행태를 비교하기 위함이다. 본 연구의 구체적 목적은 다음과 같다.

1) 대상자의 일반적 특성을 파악한다.

2) 대상자의 알레르기 질환 수에 따른 식생활 행태를 비교하여 차이를 파악한다.

\section{2. 연구방법}

\section{1 연구설계}

본 연구는 우리나라 청소년의 알레르기 질환 수에 따른 식생활 행태를 비교하기 위하여 제 15 차 (2019년) 청소년건강행태온라인조사 원시자료를 이용한 이차 분석한 서술적 조사연구이다.

\section{2 연구대상}

제15차(2019년) 청소년건강행태온라인조사는 우리나라 청소년의 건강행태를 파악하기 위해 중1 고 3 학생을 대상으로 실시하는 익명성 자기기입식 온라인조사이다. 본 연구를 위해 질병관리본부로 부터 사용승인을 받은 후 원시자료를 이용하였다.

제15차(2019년) 조사의 목표모집단은 정부승인통게(승인번호117058호) 조사로 질병관리본부에서 기관생명윤리위원회 심의를 받아 2019년 4월 기준의 전국 중·고등학교 재학생이었고, 표본설계를 위한 추출틀은 2018년 4월 기준의 전국 중·고등학교 자료를 사용하였으며, 고등학교 유형은 추출 틀 분류에 근거하여 일반계고(일반고, 자율고, 과학고, 외국어고·국제고, 예술고·체육고)와 특성화계 고(특성화고, 마이스터고)로 구분하여 사용하였다. 표본 추출과정은 모집단 층화, 표본배분, 표본추 출 단계로 나눌 수 있다. 모집단 층화 단계에서는 표본오차를 최소화하기 위해 39개 지역군과 학 교급(중학교, 일반계고, 특성화계고)을 층화변수로 사용하여 모집단을 17 개 층으로 나누었다. 표본 배분 단계에서는 층화변수별 보집단 구성비와 표본 구성비가 일치하도록 비례배분법을 적용하여 배분하였다. 표본추출은 층화집략법이 사용되었으며, 1 차 추출단위는 학교, 2 차 추출단위는 학급으 로 하였다. 본 연구를 위해 활용된 제15차(2019년)조사의 모집단 학교 수는 5,611개교, 학생 수 
$2,683,547$ 명이었고, 표본 학교 수는 800 개교, 학생 수 57,303 명이었다.

\section{3 연구도구}

본 연구에서 활용한 도구는 제15차(2019년) 청소년건강행태온라인조사 설문지로 본 연구 목적에 부합하는 일반적 특성, 식습관, 알레르기 질환과 관련된 문항을 연구변수로 선정하였다. 연구대상 자들이 작성한 온라인 자기기입식 설문 조사를 통하여 성별, 학년, 성적, 사회경제적 상태, 식습관, 알레르기 질환의 진단 여부를 조사하였다. 사회 경제적 상태는 “가정의 경제적 상태는 어떻습니 까?”라는 물음에 대해 5가지의 답안지(상, 중상, 중, 중하, 하)로 구성된 설문지를 이용하였다. 식습 관에 대해서는 9가지 종류의 식품(패스트푸드, 과자, 라면, 카페인 함유 음료, 단맛이 나는 음료, 탄 산음료, 우유, 채소, 과일)을 최근 7일 동안 어느 정도 섭취하였는지 7단계(전혀 섭취 안 함, 주 1 2회, 주 3 4회, 주 5 6회, 매일 1회, 매일 2회, 매일 3회 이상)의 답안지로 구성된 설문지를 이용 하였다. 본 연구에서는 7 단계 중 매일 1 회 이상 섭취한 군은 하나의 변수로 보았다. 알레르기 질환 의 진단여부는 이전까지 천식, 알레르기 비염 또는 아토피 피부염을 의사에게 진단받은 적이 있으 면서 “최근 12 개월 동안 알레르기 질환을 의사에게 진단받은 적이 있습니까”라는 질문에 “예”라고 응답한 학생을 '알레르기 질환이 있는군'으로 정의하였다.

\section{4 자료분석방법}

본 연구에서 SPSS/WIN 22.0 프로그램을 사용하여 다음과 같은 자료 분석 방법을 사용하였으며, 통 계학적 유의수준은 양측검정 $p<0.05$ 로 하였다. 청소년의 일반적 특성은 빈도, 백분율, 평균, 표준 편차로 제시하였다. 청소년의 알레르기 질환 수에 따른 식생활 행태의 차이를 알아보기 위하여 일 원분산분석(One-Way ANOVA)을 실시하였고, 사후검증으로 Duncan 검증을 하였다.

\section{3. 연구결과}

\section{1 대상자의 일반적 특성}

대상자 중 남학생은 $48.2 \%$, 여학생은 $51.8 \%$ 였고, 중학생은 $49.1 \%$, 고등학생은 $50.9 \%$ 였다. 도시규모 는 군지역이 $6.1 \%$, 대도시가 $44.8 \%$, 중소도시가 $49.1 \%$ 였고, 학업성취도는 '상' $14.6 \%$ '중상' $27.4 \%$. '중' $28.6 \%$, '중하' $20.7 \%$, '하' $8.7 \%$ 였다. 경제적 상태는 '상' $10.8 \%$, '중상' $30.4 \%$, '중' $45.8 \%$, '중하' $10.5 \%$, '하' $2.5 \%$ 였다([Table1]). 
[표 1] 일반적 특징

[Table 1] General Characteristics

$(\mathrm{N}=13660)$

\begin{tabular}{|c|c|c|c|}
\hline Variables & Categories & $\mathrm{n}(\%)$ & Mean \pm SD \\
\hline \multirow{2}{*}{ Gender } & Male & $6,545(48.2)$ & \\
\hline & Female & $7,045(51.8)$ & \\
\hline \multirow{6}{*}{ Grade } & Middle School 1st & $2,167(15.9)$ & \multirow{6}{*}{$3.54 \pm 1.693$} \\
\hline & Middle School 2nd & $2,137(15.7)$ & \\
\hline & Middle School 3rd & $2,367(17.5)$ & \\
\hline & High School 1st & $2,414(17.8)$ & \\
\hline & High School 2nd & $2,181(16.0)$ & \\
\hline & High School 3rd & $2,324(17.1)$ & \\
\hline \multirow{3}{*}{ Residential area } & Country & $835(6.1)$ & \\
\hline & Big city & $6,093(44.8)$ & \\
\hline & Small city & $6,662(49.1)$ & \\
\hline \multirow{5}{*}{ Achievement } & High & $1,985(14.6)$ & \multirow{5}{*}{$2.82 \pm 1.175$} \\
\hline & Moderate-High & $3,717(27.4)$ & \\
\hline & Moderate & $3,891(28.6)$ & \\
\hline & Moderate-Low & $2,807(20.7)$ & \\
\hline & Low & $1,190(8.7)$ & \\
\hline \multirow{5}{*}{ Economic status } & High & $1,471(10.8)$ & \\
\hline & Moderate-High & $4,125(30.4)$ & \\
\hline & Moderate & $6,227(45.8)$ & \\
\hline & Moderate-Low & $1,432(10.5)$ & \\
\hline & Low & $335(2.5)$ & \\
\hline
\end{tabular}

\section{2 청소년 알레르기질환 수에 따른 식생활 행태 비교}

최근 1 년간 청소년의 알레르기 질환 수에 따른 청소년 식생활 행태를 비교한 표는 Table 2 와 같 다. 알레르기 질환이 하나, 두 개, 세 개인 집단의 식생활 행태를 비교했을 때 아침식사를 하는 집 단에서 통계적으로 유의한 차이가 나타났다 $(\mathrm{F}=5.491, p=.004)$. 또한 알레르기 질환 수에 따른 세 군을 비교했을 때 탄산음료( $p<.001)$, 에너지음료 $(p<.001)$, 단맛이 나는 음료 $(p=001)$, 패스트푸드군의 섭취 빈도( $p<001)$ 가 높은 집단이 알레르기 질환이 증가하는 경향을 보였으며 통계적으로 유의한 차이를 보였다. 
[표 2] 최근 1 년간 청소년의 알레르기 질환 수에 따른 청소년 식생활 행태 비교

[Table 2] Comparison of Dietary Behavior according to the Number of Adolescent Allergic Diseases in Recent 1 Year

$(\mathrm{N}=13660)$

\begin{tabular}{|c|c|c|c|c|c|c|}
\hline \multirow[t]{2}{*}{ Variables } & Categories & $\begin{array}{c}\text { Allergic } \\
\text { disease } 1 \\
(\mathrm{n}=11625), \mathrm{a}\end{array}$ & $\begin{array}{c}\text { Allergic } \\
\text { disease } 2 \\
(\mathrm{n}=1787), \mathrm{b}\end{array}$ & $\begin{array}{c}\text { Allergic } \\
\text { disease } 3 \\
(\mathrm{n}=178), \mathrm{c}\end{array}$ & \multirow[t]{2}{*}{$\mathrm{F}$} & \multirow[t]{2}{*}{$\mathrm{p}$} \\
\hline & & & Mean \pm sd & & & \\
\hline \multirow{8}{*}{$\begin{array}{c}\text { Breakfast } \\
\text { Eating } \\
\text { habit }\end{array}$} & 0day & \multirow{8}{*}{$5.06 \pm 2.714$} & \multirow{8}{*}{$4.93 \pm 2.749$} & \multirow{8}{*}{$4.48 \pm 2.815$} & \multirow{8}{*}{5.491} & \multirow{8}{*}{$\begin{array}{l}0.004 \\
\text { (a) c) }\end{array}$} \\
\hline & 1day & & & & & \\
\hline & 2days & & & & & \\
\hline & 3days & & & & & \\
\hline & 4days & & & & & \\
\hline & 5days & & & & & \\
\hline & 6days & & & & & \\
\hline & 7days & & & & & \\
\hline \multirow{7}{*}{$\begin{array}{l}\text { Fruit } \\
\text { intake }\end{array}$} & 0 times a week & \multirow{7}{*}{$3.17 \pm 1.528$} & \multirow{7}{*}{$3.26 \pm 1.585$} & \multirow{7}{*}{$3.11 \pm 1.843$} & \multirow{7}{*}{2.919} & \multirow{7}{*}{0.054} \\
\hline & 1-2 times a week & & & & & \\
\hline & 3-4 times a week & & & & & \\
\hline & 5-6 times a week & & & & & \\
\hline & daily & & & & & \\
\hline & Twice daily & & & & & \\
\hline & $\begin{array}{c}\text { more than } 3 \text { times } \\
\text { daily }\end{array}$ & & & & & \\
\hline \multirow{7}{*}{$\begin{array}{l}\text { Soft drink } \\
\text { intake }\end{array}$} & 0 times a week & \multirow{7}{*}{$2.39 \pm 1.207^{\mathrm{a}}$} & \multirow{7}{*}{$2.50 \pm 1.312^{b}$} & \multirow{7}{*}{$2.62 \pm 1.677^{\mathrm{c}}$} & \multirow{7}{*}{8.824} & \multirow{7}{*}{$<.001$} \\
\hline & 1-2 times a week & & & & & \\
\hline & 3-4 times a week & & & & & \\
\hline & 5-6 times a week & & & & & \\
\hline & daily & & & & & \\
\hline & Twice daily & & & & & \\
\hline & $\begin{array}{c}\text { more than } 3 \text { times } \\
\text { daily }\end{array}$ & & & & & \\
\hline \multirow{7}{*}{$\begin{array}{l}\text { Energy } \\
\text { drink } \\
\text { intake }\end{array}$} & 0 times a week & \multirow{7}{*}{$1.56 \pm 1.083^{\mathrm{a}}$} & \multirow{7}{*}{$1.65 \pm 1.164^{\mathrm{b}}$} & \multirow{7}{*}{$2.07 \pm 1.736^{\mathrm{c}}$} & \multirow{7}{*}{23.434} & \multirow{7}{*}{$<.001$} \\
\hline & 1-2 times a week & & & & & \\
\hline & 3-4 times a week & & & & & \\
\hline & 5-6 times a week & & & & & \\
\hline & daily & & & & & \\
\hline & Twice daily & & & & & \\
\hline & $\begin{array}{c}\text { more than } 3 \text { times } \\
\text { daily }\end{array}$ & & & & & \\
\hline & 0 times a week & & & & & \\
\hline & 1-2 times a week & & & & & \\
\hline & 3-4 times a week & & & & & \\
\hline $\begin{array}{l}\text { Sweetened } \\
\text { drink }\end{array}$ & 5-6 times a week & $280+1292^{a}$ & $288+1356$ & $307+1595^{\mathrm{c}}$ & 6541 & 0001 \\
\hline irmk & daily & $2.00 \pm 1.292$ & & & & \\
\hline & Twice daily & & & & & \\
\hline & $\begin{array}{c}\text { more than } 3 \text { times } \\
\text { daily }\end{array}$ & & & & & \\
\hline
\end{tabular}




\begin{tabular}{|c|c|c|c|c|c|c|}
\hline \multirow{7}{*}{$\begin{array}{l}\text { Fast food } \\
\text { intake }\end{array}$} & 0 times a week & \multirow{7}{*}{$2.17 \pm 0.862^{\mathrm{a}}$} & \multirow{7}{*}{$2.20 \pm 0.931^{b}$} & \multirow{7}{*}{$2.43 \pm 1.385^{c}$} & \multirow{7}{*}{8.367} & \multirow{7}{*}{$<.001$} \\
\hline & 1-2 times a week & & & & & \\
\hline & 3-4 times a week & & & & & \\
\hline & 5-6 times a week & & & & & \\
\hline & daily & & & & & \\
\hline & Twice daily & & & & & \\
\hline & $\begin{array}{c}\text { more than } 3 \text { times } \\
\text { daily }\end{array}$ & & & & & \\
\hline \multirow{7}{*}{$\begin{array}{c}\text { Vegetable } \\
\text { intake(Kim } \\
\text { chi } \\
\text { Except) }\end{array}$} & 0 times a week & \multirow{7}{*}{$4.08 \pm 1.729$} & \multirow{7}{*}{$4.12 \pm 1.751$} & \multirow{7}{*}{$4.24 \pm 1.929$} & \multirow{7}{*}{1.132} & \multirow{7}{*}{0.322} \\
\hline & 1-2 times a week & & & & & \\
\hline & 3-4 times a week & & & & & \\
\hline & 5-6 times a week & & & & & \\
\hline & daily & & & & & \\
\hline & Twice daily & & & & & \\
\hline & $\begin{array}{c}\text { more than } 3 \text { times } \\
\text { daily }\end{array}$ & & & & & \\
\hline \multirow{7}{*}{$\begin{array}{l}\text { Milk } \\
\text { intake }\end{array}$} & 0 times a week & \multirow{7}{*}{$3.18 \pm 1.618$} & \multirow{7}{*}{$3.17 \pm 1.658$} & \multirow{7}{*}{$3.37 \pm 1.762$} & \multirow{7}{*}{1.232} & \multirow{7}{*}{0.292} \\
\hline & 1-2 times a week & & & & & \\
\hline & 3-4 times a week & & & & & \\
\hline & 5-6 times a week & & & & & \\
\hline & daily & & & & & \\
\hline & Twice daily & & & & & \\
\hline & $\begin{array}{c}\text { more than } 3 \text { times } \\
\text { daily }\end{array}$ & & & & & \\
\hline
\end{tabular}

\section{4. 논의}

본 연구는 2019년 청소년건강행태 온라인 조사의 원시자료를 바탕으로 국내 청소년의 알레르기 질 환 수와 식습관 행태 비교를 위해 시행한 연구로 알레르기 질환 수에 따른 세 군을 비교했을 때 탄산음료, 에너지음료, 단맛이 나는 음료, 패스트푸드군의 섭취 빈도가 높은 집단이 알레르기 질환 이 증가하는 통계적으로 유의한 관련성을 보였다. 이전 연구에서 햄버거나, 피자 등과 같은 패스트 푸드 섭취가 천식 및 아토피 피부염과 같은 알레르기 질환의 유병률과 관계가 된다고 보고 있다. 패스트푸드에는 마가린과 같은 액체 상태의 불포화지방을 가공하는 과정에서 생성되는 지방물질과 고기류에 함유되어 있는 패스트푸드 섭취하면서 트랜스 지방 섭취를 많이 하게 되는 원인이 되고 있다. 이러한 트랜스 지방의 섭취가 아토피 피부염이나 천식 등의 알레르기 질환과 매우 연관되어 있는 것으로 알려져 있다[12]. 이는 패스트푸드 섭취량이 증가할수록 알레르기 질환이 증가하는 관 련성을 보여주는 결과와도 이번 연구와 일치하는 연구 결과를 보였다[11].

청소년 식생활 중 최근 7일 동안 주 3 일 이상 섭취한다고 답한 경우 탄산음료, 단맛 나는 음료, 패스트푸드, 라면, 과자, 우유이었는데 이는 우리나라 청소년들이 학원, 자율학습 등으로 늦은 취침 시간이나 등교시간, 불규칙한 식습관의 문제와 간식이나 외식의 의존도가 높은 것들의 원인이고 
이런 것들이 모두 알레르기 질환에 대한 원인이 되는 큰 요인이 되는 것으로 보고되고 있는 실정 이다[13].

본 연구결과에서 아침식사가 유의한 통계적 차이가 있었는데 이는 우리나라 청소년 아침식사 결식률이 유럽이나 미국에 비해 높아지고 있다. 미국 청소년을 대상으로 시행한 연구에서 아침식 사 결식은 간식이나 패스트푸드 섭취를 증가 시켜 결국에 비만을 발생시키는 위험요인으로 보고된 바 있다[14]. 아침식사의 중요성에 대하여 비만, 생식기계 발달, 배변, 학업수행, 만성 피로 등과 관 련하여 강조하는 연구가 있다[15]. 또한 청소년의 아침 식사 여부에 따른 영양소 섭취 상태를 파악 한 연구에 따르면 아침 식사를 하지 않은 경우, 라면, 패스트푸드, 탄산음료 등 섭취가 상대적으로 많고, 우유의 섭취는 낮은 것으로 확인되었으며, 아침 식사가 성장기 적절한 성장과 발달을 위해 반드시 필요하다는 점을 강조하고 있다. 청소년의 패스트푸드 및 인스턴트 음식의 섭취는 식사속 도가 빨라지고 청소년의 충동성과 자기조절 능력의 저하를 가져오고 건강과 인성에도 영향을 주는 것으로 보고되고 있는 실정이다.

본 연구에서 청소년의 알레르기 질환 수와 식습관의 행태를 비교하여 통계적으로 식습관의 행 태에 차이가 있음을 확인하였다. 선행연구와 상이한 결과에 대해서는 추후 연구에서 재확인하는 것이 필요하다.

\section{5. 결론 및 제언}

본 연구는 제15차(2019년) 청소년건강행태 온라인조사의 원시자료를 이용하여 우리나라 청소년의 알레르기 질환 수에 따른 식생활 행태를 비교 하고자 하였다. 본 연구는 만12-18세 청소년 57,303 명을 연구대상자로 선정하였다. 연구결과는 청소년의 알레르기 질환 수와 식습관의 행태를 비교하 여 통계적으로 식습관의 행태에 차이가 있음을 확인하였다. 청소년기는 생애주기에서 삶의 질을 결정하는 매우 중요한 시기이며 특히 식생활의 행태는 신체적 건강에 매우 중요한 영향을 미치는 것으로 보고되고 있다. 알레르기 질환은 조기 진단하여 치료하거나 진행의 예방 차원에서 매우 중 요하다. 따라서, 앞으로 청소년의 알레르기 질환수가 많은 학생들이 신체적 건강 상태가 취약한 것 을 확인하게 되었고, 이에 따라 청소년의 식생활을 명확히 파악하여 식생활 개선을 위한 긍정적인 식습관 및 정서적 안정과 스트레스 해소를 위한 가정과 학교, 지역사회, 국가 등 체계적인 영역에 서 다차원적인 노력이 뒷받침 되어야 할 것이다. 이에 추후 연구에서는 본인의 알레르기 과거력 이나 가족력 등의 다양한 변수들을 포함하는 종단적 연구의 반복 연구를 제언한다.

\section{References}

[1] K. M. Ahn, J. H. Kim, H. J. Kwon, Y. M. Chae, M. I. Hahm, K. J. Lee, Y. M. Park, S. Y. Lee, W. K. Kim, M. Y. Han, The prevalence of symptoms of asthma, allergic rhinoconjunctivitis, and eczema in Korean children: nationwide cross-sectional survey using complex sampling design, Jounal of Korean 
Medical Associaion, (2011), Vol.54, No.7, pp.769-778, UCI: G704-002228.2011.54.7.001

[2] H. S. Ahn, Pediatrics, 10th edition, Mirae N, (2012), p.1110-1119.

[3] https://kosis.kr/index/index.do, Jun 7 (2020)

[4] G. R. Maslow, A. A. Haydon, C. A. Ford, C. T. Halpern, Young adult out-comes of children growing up with chronic illness: an analysis of the National Longitudinal Study of Adolescent Health, Archives of Pediatrics and Adolescent Medicine, (2011), Vol.165, No.3, pp.256-261, DOI: 10.1001/archpediatrics.2010.287

[5] H. J. Kim, M. A. Han, S. H. Kim, S. M. Park, J. Park, S. Y. Ryu, S. W. Choi, Associations between cigarette smoking, alcohol drinking, and lifetime diagnosis of atopic dermatitis in Korean boys and girls: the Eighth Korea Youth Risk Behavior Web-based Survey, Journal of the Korean Society of Maternal and Child Health, (2014), Vol.18, No.2. pp.175-185, DOI: 10.21896/jksmch.2014.18.2.175

[6] M. H. Park, S. Y. Yim, Relationships between dietary behaviors, health behaviors, and depression among the middle and high school students in Korea, Journal of the Korean Data Analysis Society, (2014), Vol.16, No.5, pp.2683-2694, UCI: G704-000930.2014.16.5.018

[7] J. E. Jo, H. R. Park, S. B. Jeon, J. S. Kim, G. E. Park, Y. Li, Y. S. Lim, J. A. Hwang, A Study on Relationship between Socio-demographic Factors and Food Consumption Frequencies among Adolescents in South Korea: Using the Korea Youth Risk Behavior Web-based Survey from 2011, Korean Journal of Community Nutrition, (2013), Vol.18, No.2, pp.165-176, UCI: G704-000212.2013.18.2.005

[8] The 13th Korea youth risk behavior web-based survey, Ministry of Education, Ministry of Health and Welfare, Korea Centers For Disease Control \& Prevention, (2013)

[9] J. H. Kim, Mental health in adolescents with allergic diseases-using data from the 2014 Korean youth's risk behavior web-based study, The Journal of the Korean Society of School Health, (2015), Vol.28, No.2, pp.79-88, UCI: G704-001960.2015.28.2.004

[10] W. C. Wu, H. Y. Chang, K. N. Kuo, C. Y. Chen, Y. C. Tu, Y. H. Yang, Psychosocial problems in children with allergic diseases: a population study in Taiwan, Child: Care, Health and Development, (2010), Vol.37, No.5, pp.662-670, DOI: https://doi.org/10.1111/j.1365-2214.2011.01207.x

[11] M. S. Kim, C. H. Youn, A. S. Kim, H. J. Ko, H. M. Kim, H. S. Kim, J. H. Kwon, Food habits and allergic disease in korean adolescent, Korea Journal of Family Practice, (2017), Vol.7, No.2, pp.179-187, DOI: $10.21215 / \mathrm{kjfp} .2017 .7 .2 .179$

[12] G. Nagel, G. Weinmayr, A. Kleiner, L. Garcia-Marcos, D. P. Strachan, Effect of diet on asthma and allergic sensitisation in the International Study on Allergies and Asthma in Childhood (ISAAC) phase two, Thorax, (2010), Vol.65, No.6, pp.516-522, DOI: 10.1136/thx.2009.128256

[13] J. H. Lee, M. Kwon, The effect of eating behaviors on subjective happiness in adolescents, The Journal of Korean Society of School Health, (2018), Vol.31, No.1, pp.39-47.

[14] H. M. Niemeier, H. A. Raynor, E. E. Lloyd-Richardson, M. L. Rogers, R. R. Wing, Fast food consumption and breakfast skipping: Predictors of weight gain from adolescence to adulthood in a nationally representative sample, The Journal of Adolescent Health, (2006), Vol.39, No.6, pp.842-849, DOI: 10.1016/j.jadohealth.2006.07.001

[15] K. Y. Park, Breakfast and health in adolescents, Pediatric Gastroenterology, Hepatology \& Nutrition, (2011), Vol.14, No.4, pp.340-349, UCI: G704-001424.2011.14.4.008 